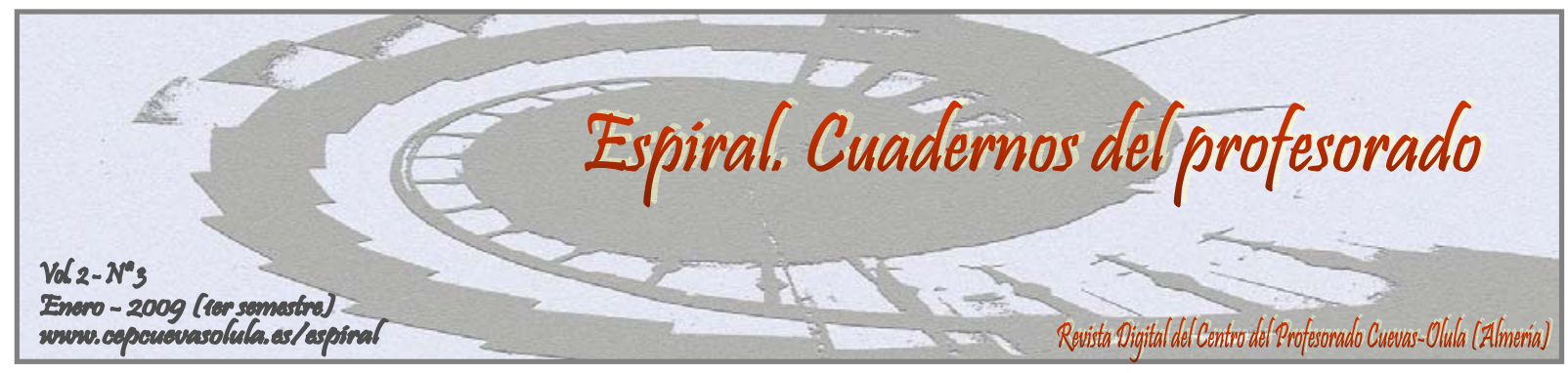

\title{
LA MÚSICA EN LA HISTORIA GENERAL DE LAS COSAS DE NUEVA ESPAÑA DE FRAY BERNARDINO DE SAHAGÚN
}

\author{
THE MUSIC IN THE GENERAL HISTORY OF THINGS OF NEW SPAIN FRAY \\ BERNARDINO DE SAHAGUN
}

\section{Emilia Martos Sánchez}

\section{I.E.S. Mar de Poniente, La Línea de la Concepción, Cádiz (España)}

Martos Sánchez, E. (2009). La música en La Historia General de las Cosas de Nueva España de Fray Bernardino de Sahagún. [en línea]. Espiral. Cuadernos del Profesorado, 2(3), 66-73. Disponible en: http://www.cepcuevasolula.es/espiral.

Enviar correspondencia a: martosemi@gmail.com

RESUMEN: Este artículo realiza un análisis musical de la crónica de indias, La Historia General de las Cosas de Nueva España, escrita por el franciscano fray Bernardino de Sahagún. Las crónicas constituyen una fuente documental importantísima para la investigación de los primeros momentos de la conquista del Nuevo Mundo; asimismo la labor desarrollada por los evangelizadores como Sahagún es significativa, ya que gracias a sus testimonios podemos conocer muchos datos de la primera etapa colonizadora. Esta obra, así como el resto de la producción literaria de Sahagún, nos ofrece una enriquecedora visión de la historia, la cultura y las costumbres de los indígenas, en la cual la música adquiere una notoriedad evidente. Las referencias a la música insertas en la crónica son de muy diversa índole, tratando temas como el canto, la danza, las interconexiones musicales entre el Viejo y el Nuevo Mundo, la música en términos generales, así como su presencia y funcionalidad en el pueblo nahua.

Palabras clave: crónicas, indígenas, música.

ABSTRACT: This article undertakes the musical analysis of the Spanish Chronicles from the Indies, General History of New Spain's Things, written by the Franciscan Brother Bernardino de Sahagún. The chronicles represent a very important documentary source for the research on the first moments of the Spanish Conquest of the New World; likewise the task carried out by the Christian colonizers as Sahagún is significant, since, thanks to their testimonies we can obtain numerous data points of the first period in the colonization. This particular work, like the rest of Sahagún's literary productions, offers us a rich vision of the history, the culture and the customs of the natives, in which music achieves obvious notoriety. References to music found in the chronicles are of various kinds dealing with topics like singing, dancing, the musical interconnections between the Old and the New World, music itself deal with in general terms, as well as its presence and function among the Nahua people.

Key words: chronicles, natives music. 


\section{1.- INTRODUCCIÓN.}

Con este trabajo, pretendemos hacer un estudio musical de La Historia General de las Cosas de Nueva España, una crónica de indias escrita por el fraile franciscano Fray Bernardino de Sahagún. Para ello, nos hemos propuesto un doble objetivo: extraer todas las referencias musicales existentes en la misma ${ }^{1}$ y hacer un análisis musicológico a partir de éstas.

El presente estudio se estructura en tres secciones fundamentales. La primera de ellas analiza la vida de Fray Bernardino de Sahagún, así como la producción literaria desarrollada por el mismo a lo largo de su vida. La segunda sección aborda el estudio de la Historia General de las Cosas de Nueva España desde un punto de vista general, para terminar con una tercera dedicada exclusivamente al análisis musicológico de la crónica.

En cuanto al estado de la cuestión, hemos de señalar que no existe un estudio musicológico específico sobre la Historia General de las Cosas de Nuevas España de Fray Bernardino de Sahagún. No obstante, sí son muchas las investigaciones así como el interés despertado por la música precortesiana de México, tal como afirma Robert Stevenson (1996). Entre los principales estudios ${ }^{2}$ destacan los de Thomas Stanford, Samuel Martí, Pablo Castellanos y Robert Stevenson.

\footnotetext{
${ }^{1}$ En este artículo sólo aparecerán las referencias musicales más importantes con objeto de ceñirnos adecuadamente a las normas de publicación.

${ }^{2}$ Stevenson, R. (1996). Reflexiones sobre el concepto de música precortesiana en México. Heterofonía: Revista de Investigación musical, vol. XXX/114-115, 25-37; Stevenson, R. (1952). Early Aboriginal music en Mexico. Music in Mexico: a historical survey. New Cork: Thomas Y. Crowell Company; Stanford, Th. (1999). Aztecas. En Emilio Casares (Ed.), Diccionario de la Música Española e Hispanoamericana (vol. I, p. 944). Madrid: Sociedad General de Autores y Editores.; Stanford, Th. (1996). A linguistic Analysis of music an Dance Terms from Three SixteenthCentury Dictionaries of Mexican Indian Languages. Yearbook of the Inter-American Institute for Musical Research, 2; Martí, S. (1951). Música de los Azteca. Organología Precolombina. Cuadernos Americanos, 10, 56. Martí, S. (1953). Flautilla de la Penitencia. Cuadernos Americanos, 12, 72; Martí, S. (1954). Música Precortesiana. Cuadernos Americanos, 13, 78; Martí, S. (1968). Instrumentos musicales precortesianos. México: Instituto Nacional de Antropología e Historia; Castellanos, P. (1970). Horizontes de la Música precortesiana. México: FCE.
}

A la hora de abordar un estudio de estas características, ha de tenerse en cuenta también, las crónicas de indias, las fuentes arqueológicas, así como las fuentes iconográficas.

Actualmente, lo que se conoce sobre la música de los indígenas, se puede resumir en trece puntos, destacados por Stevenson (1996) y que derivan del testimonio de los cronistas españoles. Estos son los siguientes (p. 36-37):

1. No existía la idea de música en nuestro sentido moderno de un arte destinado a las salas de concierto.

2. La música azteca era inseparable de las ceremonias religiosas.

3. Existía una clase de músicos profesionales que controlaba el uso de la música en las ceremonias.

4. Se imponía una educación sumamente rigurosa a todos los que aspiraban a actuar en contextos que incluían música y se les exigía una ejecución perfecta, ya que cualquier error podía ofender al dios que se honraba. Los errores eran, por lo tanto, literalmente fatales, pues se daba la pena de muerte a cualquier músico culpable de una equivocación.

5. Tanto cantantes como instrumentistas gozaron de un elevado prestigio social y de la exención de tributos.

6. No es posible saber los nombres de los músicos, con excepción de príncipes o reyes como Nezahualcóyotl de Texcoco.

7. La norma imperante era la música como expresión de la vida de la comunidad, no así la música creada por un solista.

8. El concepto de música incluía siempre el canto, la danza y los instrumentos, nunca el canto solo.

9. A varios instrumentos se les atribuyó un origen celestial, como al huéhuetl, tocado con las palmas y los dedos de las manos, y al teponaztli, tocado con las baquetas con la punta cubierta de hule (llamadas olmaitl).

10. Cada trozo de música estaba destinado a un momento previamente designado: una ceremonia fija, un día del calendario de 26 meses. Los sacerdotes hacían presagios para cada día del ciclo de 260 días y los músicos debían estar listos con cantos y tonos especiales para cada día del ciclo religioso.

11. Debido a la ausencia de escritura musical, los músicos tuvieron que aprender 
de memoria una cantidad enorme de cantos y piezas instrumentales.

12. La habilidad creativa también era un requisito que los músicos debían cumplir, ya que en ocasiones los caciques más poderosos necesitaban de nuevos cantos con el objeto de preservar el recuerdo de sus hazañas y proezas.

13. No existían instrumentos de cuerda, había solamente instrumentos de percusión, de soplo, para raspar y agitar.

\section{2.- FRAY BERNARDINO DE SAHAGÚN Y SU PRODUCCIÓN LITERARIA}

Bernardino de Ribera (ca. 1500-1590), más conocido como Fray Bernardino de Sahagún ${ }^{3}$, fue un destacado fraile franciscano entre aquellos que marcharon a América con la misión de evangelizar a los indígenas que allí habitaban.

Estudió en la Universidad de Salamanca, ordenándose como sacerdote en 1524. Cinco años más tarde partió hacia Nueva España, junto a otros diecinueve frailes, en una expedición dirigida por Fray Antonio Ciudad.

Dedicó gran parte de su vida al estudio de la lengua, la historia y las costumbres del pueblo nahua, razón por la que se le considera, en opinión de Tudela (1952), fundador de los estudios de la literatura nahua e incluso de la moderna etnología (1091-1092).

La enseñanza constituyó otra de sus tareas principales. En 1532 estuvo en el Convento de Tlamanalco, marchándose cuatro años después al Imperial Colegio de Santa Cruz de Tlatelolco, en el que se le encomendó la enseñanza del latín a los jóvenes indios, muchos de los cuales colaborarían más tarde en su obra. En 1558 viaja a Tepepulco, y a partir de 1560 y hasta su muerte, vivirá a caballo entre Tlatelolco y San Francisco de México.

La enorme producción literaria de Sahagún fue fruto de una incesante investigación, en la que recuperó numerosos datos acerca de la cultura, creencias, artes y costumbres de los naturales de Nueva España. Para llevar a cabo esta tarea, puso en funcionamiento un moderno método de investigación a través del cual realizaba cuestionarios en nahuatl, que eran leídos a los indios que encabezaban los barrios o parcialidades. Estos indios se encargaban de

\footnotetext{
${ }^{3}$ Este apellido procede del nombre del pueblo en el que Francisco de Ribera nació.
}

ponerle en contacto con los indígenas más ancianos, los cuales prestaron una gran ayuda y fueron conocidos como los "informantes" de Sahagún, quienes procedían de tres ciudades distintas: Tepepulco, Tlatelolco, y Ciudad de México.

Escribió también numerosas obras de carácter catequístico, entre las cuales encontramos confesionarios, sermonarios, catecismos, entre otras. Pero sin duda alguna, su obra fundamental es la Historia de las Cosas de Nueva España.

\section{3.- HISTORIA GENERAL DE LAS COSAS DE NUEVA ESPAÑA DE FRAY BERNARDINO DE SAHAGÚN.}

La Historia General de las Cosas de Nueva España es una obra paradigmática no sólo en la producción de Sahagún, sino también desde el punto de vista histórico, etnográfico o lingüístico.

Los estudiosos del tema no se ponen de acuerdo a la hora de datar esta obra literaria. La mayor parte de éstos, entre los que destaca Zavadkivker (1999), sitúan su creación entre 1557 y 1577 (p. 194). Sin embargo, en la edición que hace Garibay (1969) de esta obra se nos facilitan una serie de datos que justificaría el que situe la obra entre 1547 y 1582 (p. 7-23). Afirma, en base a una nota inserta en la crónica ${ }^{4}$, que desde 1547 hasta 1577, Sahagún se dedicó a recoger toda la documentación necesaria para su posterior redacción, comenzándose esta versión en castellano en 1577. No obstante, los años transcurridos entre 1569 y 1575 constituyen un período de inactividad.

Dado este proceso de elaboración, Garibay considera que existen dos obras paralelas: la de los indios, escrita en nahuatl entre los años 1547 y 1577, y la de Sahagún, escrita en castellano entre 1577-1582. Ambas obras, no coinciden en frecuentes ocasiones, pero no puede entenderse la una sin la otra, según Garibay (1969, p. 12):

"Así las dos obras son como piedra de toque una de otra. En ellas se entrelazan los dos modos de concebir el mundo. Sahagún queda influido por los indios aun en su estilo. Los indios,

\footnotetext{
4 "Fue traducido en lengua española (...) después de treinta años que se escribió en la lengua mexicana en este año de 1577”. En Sahagún, B. (1969). Historia General de las cosas de Nueva España (Libro VI, Capítulo XLIII, p. 240). Ángel María Garibay (ed.). México: Porrúa.
} 
necesariamente, sufren su influjo, pero conservan su propia manera de ver, de pensar, de expresar, y su lengua sonora, elegante y matizada, hasta un grado que ninguna lengua de las conocidas hoy día tiene el caudal y la delicadeza de expresión y finura de ella".

Los dos documentos se conservan en el Códice de Florencia en dos columnas. Este Códice no es el más antiguo (finales del siglo XVI aproximadamente), ni el más preciso, pero sí valioso porque contiene muchos textos originales y únicos- de la versión indígena. De mayor interés para Garibay son los manuscritos conservados en Madrid, que aunque incompletos, están más acreditados por Sahagún y poseen una mayor antigüedad.

Otra cuestión controvertida ha sido la autoría del encargo de La Historia General de las Cosas de Nueva España. Aunque en palabras del mismo Sahagún, fue Francisco del Toral el que le encargó la elaboración de la obra, para Garibay habría sido el padre Motolinía quién lo hiciese, dado que en 1547 era éste el que estaba al frente de la Orden.

La obra en su conjunto aporta una completa visión sobre la historia, la cultura, y las costumbres de estos indígenas, donde la música, como veremos en el próximo apartado, tiene un papel fundamental. Sahagún divide la obra en doce libros, tratando en cada uno de ellos distintos temas de la vida de los naturales de Nueva España.

Desde su creación, han sido varias las ediciones realizadas sobre la obra, tal como indica Zavadkivker (1999, p. 194). La primera de ellas, realizada a partir de una descuidada copia del Codice Florentino, fue publicada por Carlos María Bustamante en México en 1829-30. Esta fue seguida por la edición de Robredo en 1938 y la edición de Nueva España de 1946, ambas basadas en copias parciales del Códice. En 1956, la Editorial Porrúa, bajo la supervisión de Garibay, publicará una nueva edición de $L a$ Historia General de las Cosas de Nueva España, que se reeditará en 1969. En 1988, Alianza Editorial hace una nueva edición en la que se contiene íntegro el texto castellano del Códice Florentino. Pero será a partir de 1979, con la edición facsimilar realizada por la Secretaria de Gobernación de México, cuando los estudios sobre Sahagún adquieran una nueva perspectiva.
La segunda edición de Porrúa es con la que hemos trabajado, debido a que es en la que más fuentes se cotejan. En efecto, en ella se contrasta la copia fotográfica del Códice Florentino, con los Manuscritos de Madrid, a la vez que revisa la edición de Robredo. Además, sin modificar la puntuación, realiza una división en párrafos del texto original, que la hace más legible.

\section{4.- METODOLOGÍA.}

La Historia de Sahagún, está plagada de innumerables referencias a la cultura y costumbres del pueblo nahua, incluyéndose en éstas la música.

La mayor parte de las noticias musicales se concentran en el libro II, que trata sobre los calendarios, las fiestas y las ceremonias. No obstante, el resto de los libros no dejan de poseer importancia, pese a que el número de alusiones musicales sea mucho menor.

Estas noticias pueden agruparse en tres grandes bloques temáticos. El primero de estos bloques versa sobre la música en términos generales, así como su presencia y funcionalidad en el pueblo nahua. El segundo trata sobre el canto, la danza, los instrumentos musicales. En el último bloque se intenta plasmar las posibles interconexiones musicales entre el Viejo y el Nuevo Mundo.

\section{La música indígena, presencia y \\ funcionalidad.}

La música indígena no constituye una manifestación aislada, sino que se asocia al canto y a la danza constituyendo una unidad, tal como indica Irene Vazquez Valle (1999, p. 497). Además, no existe un término en la lengua nahua que se identifique con nuestro concepto de música. Stevenson (1996, p. 31) señala como próximo, el término cuícatl que significaba canto y era combinado con una gran variedad de palabras. La mencionada interconexión se puede apreciar en citas como ésta:

" $Y$ en matando a uno, tocaban los instrumentos musicales, $y$ en cesando tomaban otro para matarle, $y$ en matándole tocaban otra vez, y así hacían a cada uno hasta acabarlos; acabando de matar estos tristes, comenzaban a bailar y cantar, a comer y a beber, y así se acababa la fiesta”. (Sahagún, 1969, Libro II, Capítulo XV, p. 128, párrafo 2). 
Tabla 1. Clasificación de los Instrumentos musicales mencionados por Sahagún.

\begin{tabular}{llll}
\hline PERCUSIÓN & VIENTO & CUERDA & OTROS \\
\hline Atambores & Flauta & Vihuela & Órgano \\
Teponaztli & Cornetas & & \\
Sonajas & Trompetas & & \\
Caracolitos & Chiflos de barro & \\
Atabal & cocido & \\
Ayochicahuaztli ó Nahualeuahuitl & Pitos & \\
Cascabeles & Pífano & \\
Tecomapiloa & Caracoles & \\
Chicauaztli & marinos & \\
Cuechtli & Sacabuche & \\
Tamboril & Chiflos & \\
Ayacachtli & Chirimías & \\
Tetzilacatl & & \\
Omichicauatztli & & \\
\hline
\end{tabular}

La música representa una forma de expresión comunitaria que se hace presente en ceremonias religiosas, en celebraciones para honrar a gobernantes o personajes de élite, así como en los conflictos bélicos.

El ceremonial religioso, íntimamente ligado a la música, se servía de ésta como un puente de comunicación entre la humanidad y los dioses. Sin embargo, una defectuosa interpretación musical en el ritual, en palabras de Irene Vazquez $(2000)^{5}$ podía ofender a los dioses y pagarse muy caro por el error, así como si la interpretación era buena, ésta podía suponer una recompensa para el ejecutante (p. 498):

"De esta misma librea arreaba a todos los principales, y hombres de guerra y capitanes, y todas las otras gentes que habían de entrar en la danza o baile; y también a todos daba copiosamente de comer y beber. $Y$ andando en el baile, si alguno de los cantores hacía falta en el canto, o si los que tañían el teponaztli y atambor faltaban en el tañer, o si los que guían erraban en los meneos y contenencias del baile, luego el señor les mandaba prender y otro día los mandaba matar". (Sahagún, 1969, Libro VIII, Capítulo XVII, Episodio 3, p. 319, párrafo 5).

No obstante, en la sociedad azteca, la figura del músico o cantor gozaba de un alto prestigio social, recogiéndose incluso como oficios, el de tañedor y el de cantor.

\footnotetext{
${ }^{5}$ Vazquez, “México. I. Precolombina”, 498.
}

"A los que nacían en este signo [ce ozomatli], varones, decían que serían bien acondicionados y regocijados, $y$ amigos de todos; y que serían cantores o bailadores, o pintores, o aprenderían algún buen oficio por haber nacido en tal signo". (Sahagún, 1969, Libro IV, Capítulo XXII, p. 349, párrafo 2).

En definitiva, la música constituía una actividad primordial, que según Stevenson (1996) se aprendería de memoria debido a la ausencia de escritura musical (p. 26). En efecto, a lo largo de La Historia no se hacen referencias a la existencia de algún tipo de notación, y además, Sahagún incluye en la crónica los textos de diversos cantos a los Dioses sin las melodías musicales de éstos.

\section{Instrumentos musicales, Canto y Danza:}

En la Historia General de las Cosas de Nueva España, aparecen numerosas noticias referentes a los instrumentos musicales, que nos permiten elaborar unas conclusiones claras sobre la organología indígena.

Parece evidente la preponderancia de los instrumentos de percusión, seguidos de los aerófonos. Sin embargo, no se registra el uso de cordófonos entre los indígenas, a excepción de una vihuela, que sería una aportación hecha por los españoles a su llegada a América.

En el caso de la percusión, éstos podían ser accionados directamente, así como formar parte de los lujosos vestuarios de danza que llevaban los grandes señores aztecas y que al moverse, producirían distintos sonidos musicales: 
"Tenía [la diosa Uixtocihuatl en las gargantas de los pies atados cascabeles de oro, o caracolitos blancos, estaban ingeridos en una tira de cuero de tigre; cuando andaba hacían gran sonido". (Sahagún, 1969, Libro II, Capítulo XXVI, p. 172, párrafo 3).

Los instrumentos a los que alude Sahagún son muy variados, como puede constatarse en la tabla 1, estando algunos al servicio de los rituales, como es por ejemplo el caso de la flauta:

"Llegado a las gradas del cu, él mismo se subía por las gradas arriba, y en la primera grada hacía pedazos una de las flautas con que tañía en el tiempo de su prosperidad, y en la segunda grada hacía pedazos otra y en la tercera otra, y así las acababa todas, subiendo por las gradas”. (Sahagún, 1969, Libro II, Capítulo XXIV, p. 155, párrafo 23).

En cuanto al Canto, y como señala Vazquez Valle (1999, p. 498), "se consideraba un lenguaje, un medio de comunicación realizado tanto por los instrumentos musicales como por la voz humana”, ligado a la danza y a la música. Son muchas las alusiones referidas al canto en esta crónica, tal como se refleja en el siguiente ejemplo:

"No danzaban a manera de areito, ni hacían los meneos como en el areito, sino iban paso a paso al son de los que tañían y cantaban, los cuales estaban todos en pie, apartados un poco de los que bailaban”. (Sahagún, 1969, Libro II, Capítulo IX, p. 120, párrafo 2).

En algunas de ellas, se habla de una particular forma de cantar, lo cual evidenciaría que los aztecas distinguían texturas o calidades de voces. Existían también distintos tipos de cantares en función del momento, que se adecuaban a una indumentaria determinada.

"Había otra sala que se llamaba mixcoacalli. En este lugar se juntaban todos los cantores de México y Tlatilulco, aguardando a lo que les mandase el señor, si quisiese bailar, o probar u oír algunos cantares de nuevo compuestos, $y$ tenían a la mano aparejados todos los atavíos del areito, atambor y atamboril, con sus instrumentos para tañer el atambor y unas sonajas que se llaman ayacachtli, $y$ tetzilacatl, $y$ omichicauatztli, y flautas, con todos los maestros tañadores $y$ cantores $y$ bailadores, y los atavíos del areito para cualquier cantar. Si mandaban el señor que cantasen los cantares de Uexotzincáyotl, o Anahuacáyotl, así los cantaban y bailaban con los atavíos daba a los maestros y cantores que cantasen y bailasen el cantar que se llama Cuextecáyotl, tomaban los atavíos del areito conforme al cantar y se componían con cabelleras y máscaras pintadas, con narices agujeradas y cabellos bermejos, $y$ traían la cabeza ancha y larga como lo usan los cuextecas, y traían las mantas tejidas a manera de red. De manera que los cantores tenían muchas y diversas maneras de atavíos, de cualquier areito, para los cantares y bailes”. (Sahagún, 1969, Libro VIII, Capítulo XIV, p. 313, párrafos 1-3).

Sahagún incluye una gran cantidad de himnos a los dioses, de los cuales, como he señalado anteriormente, no nos ha llegado ninguna melodía.

El último elemento de este ambiguo concepto de música es la Danza. Las danzas, impregnadas de gran simbolismo y religiosidad, estaban presentes en todas las ceremonias religiosas. "La vigilia de esta fiesta cantaban y danzaban todas las mujeres, viejas y mozas y muchachas" (Sahagún, 1969, Libro II, Capítulo VII, p. 117, párrafo 2).

Son muy ricas las descripciones que Sahagún realiza sobre la indumentaria utilizada, así como la forma de ejecución de algunos bailes. De estas descripciones se sobreentiende que existían bailes en función de la ocasión, en los cuales podían participar hombres y mujeres juntos, o individualmente.

“También en esta danza entraban mujeres, mozas públicas (...); y danzaban culebreando y cantando, y los que hacían el son para la danza, y los que regían el canto estaban juntos, arrimados a un altar redondo que llamaban momoztli. En esta danza no hacían ademanes ningunos con los pies ni con las manos, ni con las cabezas, ni hacían vueltas ningunas, más de ir con pasos llanos al compás del son y del canto, muy despacio; nadie osaba hacer ningún bullicio, ni atravesar por el espacio donde danzaban; todos los danzantes iban con gran tiento, que no 
hiciesen alguna disonancia (...). A la puesta del sol cesaba este areito y se iban todos para sus casas, y lo mismo hacían en cada casa, cada uno delante de sus dioses; había gran ruido en todo el pueblo por razón de los cantares y del tañer de cada casa” (Sahagún, 1969, Libro II, Capítulo XXVIII, pp. 183-184, párrafos 7-10).

\section{Interconexiones entre el Viejo y el Nuevo mundo:}

A lo largo de la crónica, no son muchas las referencias a imbricaciones entre prácticas musicales del viejo y del nuevo mundo. No obstante, sí podemos constatar algunas alusiones que reflejan una posible influencia del Nuevo Mundo, aunque también es cierto, que algunas de éstas puedan deberse al mero hecho de que la persona que escribe, lo hace con una terminología española. La aplicación de las palabras chantre y salmos, son producto del vocabulario preconcebido de Sahagún, que posiblemente vio semejanzas con determinadas prácticas aztecas, y los empleó en este contexto.

Sí se pueden ver influencias españolas en las danzas indígenas. De algunas citas se desprende como se había adoptado el compás utilizado en las danzas de Castilla.

"Los hombres que iban danzando no iban entre las mujeres, porque las mujeres iban todas juntas rodeadas de Xilónen, que era la que había de morir, iban cantando y bailando; a las mujeres íbanlas tañendo con un teponaztli que no tenía mas que una lengua encima y otra debajo, y en la de abajo llevaba colgada una jícara en que suelen beber agua, $y$ así suena mucho más que los que tienen dos lenguas en la parte de arriba, y ninguna abajo. A este teponaztli llamaban tecomapiloa; llevábale uno debajo del sobaco, tañéndole, por ser de esta manera hecho. Los gentiles hombres que iban bailando iban delante y no llevaban aquel compás de los areitos, sino el compás de las danzas de Castilla la Vieja, que van unos trabados de otros y culebreando (...). Y uno de los sátrapas llevaba delante la tabla de las sonajas, de que habemos hablado atrás. En llegando al cu del dios que se llamaba Cintéotl, donde había de morir esta mujer, poníase delante de ella el sátrapa que llevaba la tabla de las sonajas, que se llamaba chicauaztli, y poníanla enhiesta delante de ella y comenzaba a hacer ruido con las sonajas, meneándole a una parte y a otra" (Sahagún, 1969, Libro II, Capítulo XXVII, pp. 180-181, párrafos 48-52).

Pero, indiscutiblemente, la referencia más explícita a la simbiosis entre prácticas indígenas y españolas es el relato de la celebración de las vísperas de San Antonio de Papua, en el que se constata como los españoles habían enseñado a los indígenas la doctrina cristiana.

“[...] y este día, que era víspera de S. Antonio de Padua, se celebraron sus vísperas con mucha solemnidad, que fueron las primeras que sucedieron en esta tierra, y el día siguiente la misa cantada con mucha pompa, que fue la primera que dijeron allí estos religiosos en la nueva España, hallándose en ella Cortés y todos los españoles, $e$ Ixtlilxuchitl con todos los señores, sus hermanos y deudos, que oyeron con mucha atención la misa, y se enternecieron tanto, que de contentos lloraron en ver lo que mucho ellos deseaban especialmente que ellos sabían muy bien los misterios de la misa, porque el P. Fr. Pedro de Gante, como mejor pudo y con la gracia de Dios (que era lo más cierto), les enseñó la doctrina cristiana, y los misterios de la pasión, y vida de nuestro Señor Jesucristo, y la ley evangélica, desde que vino a esta tierra; y así cuando oyeron esta primera misa bien sabían lo que era, de lo cual Ixtlilxuchitl se derretía en lágrimas que ponía devoción y espanto a los religiosos y españoles que presentes estaban" (Sahagún, 1969, Libro XII, Relato de Alva, p. 243, párrafo 262).

Aunque existen algunas noticias sobre estas interconexiones entre los dos mundos, la pretensión fundamental en la Historia General de las Cosas de Nueva España es recoger lo propio del pueblo nahua, sus características más distintivas y sus costumbres.

\section{5.- CONCLUSIONES.}

La figura de Sahagún, así como la del resto de los cronistas de indias, es esencial en el estudio de todo aquello relacionado con las Indias Occidentales. Sus obras, y su encomiable trabajo 
nos permite acercarnos a un mundo lejano, del que tenemos noticias gracias a ellos.

La Historia General de las Cosas de Nueva España de Sahagún, refleja la importancia de la música para aquellos a quienes describe, dentro de un conjunto de descripciones y relatos que hacen de la obra una pieza fundamental para el conocimiento de la cultura indígena, así como para entender el nacimiento de la etnografía moderna.

\section{6.- REFERENCIAS BIBLIOGRÁFICAS.}

Sahagún, B. (1969). Historia General de las cosas de Nueva España. Ángel María Garibay (ed.), 4 vols. Mexico: Porrúa.

Stanford, Th. (1999). Aztecas. En Emilio Casares (Ed.), Diccionario de la Música Española e Hispanoamericana (vol. I, p. 944). Madrid: Sociedad General de Autores y Editores.
Stevenson, R. (1996). Reflexiones sobre el concepto de música precortesiana en México. Heterofonía: Revista de Investigación musical, vol. XXX/114-115, pp. 25-37.

Tudela, J. (1952). Fray Bernardino de Sahagún. En VV.AA., Diccionario de Historia de España desde sus orígenes hasta el fin del reinado de Alfonso XIII (vol. II, pp. 10911092). Madrid: Revista de Occidente.

Vázquez Valle, I. (2000). México. I. Precolombina. En Emilio Casares (Ed.), Diccionario de la Música Española e Hispanoamericana (vol. VII, pp. 496-500). Madrid: Sociedad General de Autores y Editores.

Zavadivker, R. (1999). Cronistas de indias. En Emilio Casares (Ed.), Diccionario de la Música Española e Hispanoaméricana (vol. IV, pp. 187-205). Madrid: Sociedad General de Autores y Editores.

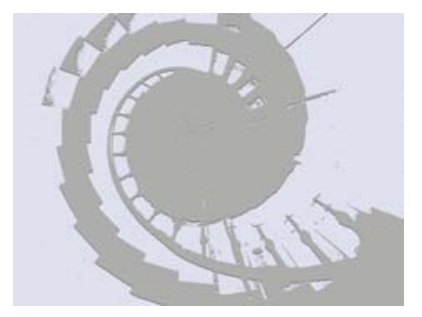

